\title{
Iron isotopic fractionation during continental weathering
}

\author{
Matthew S. Fantle ${ }^{1 *}$, Donald J. DePaolo ${ }^{1,2}$ \\ ${ }^{1}$ University of California, Department of Earth and Planetary Science \\ Center for Isotope Geochemistry \\ 307 McCone Hall \\ Berkeley, CA 94720-4767 \\ E-mail: mfantle@eps.berkeley.edu \\ Telephone: 510.642.9116, Fax: 510.642.9520 \\ ${ }^{2}$ MS 90-1160 \\ Earth Sciences Division \\ E.O. Lawrence Berkeley National Laboratory \\ Berkeley, CA 94720 \\ E-mail: depaolo@eps.berkeley.edu \\ Telephone: 510.643.5064, Fax: 510.642.9520 \\ * Corresponding author \\ Main text word count: 5291 words \\ Estimated published length: 15.5 pages
}




\begin{abstract}
The biological activity on continents and the oxygen content of the atmosphere determine the chemical pathways through which Fe is processed at the Earth's surface. Experiments have shown that the relevant chemical pathways fractionate Fe isotopes. Measurements of soils, streams, and deep-sea clay indicate that the ${ }^{56} \mathrm{Fe} /{ }^{54} \mathrm{Fe}$ ratio $\left(\square^{56} \mathrm{Fe}\right.$ relative to igneous rocks) varies from $+1 \%$ for weathering residues like soils and clays, to $-3 \%$ for dissolved Fe in streams. These measurements confirm that weathering processes produce substantial fractionation of Fe isotopes in the modern oxidizing Earth surface environment. The results imply that biologically-mediated processes, which preferentially mobilize light Fe isotopes, are critical to Fe chemistry in weathering environments, and that the $\square^{56} \mathrm{Fe}$ of marine dissolved $\mathrm{Fe}$ should be variable and negative. Diagenetic reduction of $\mathrm{Fe}$ in marine sediments may also be a significant component of the global Fe isotope cycle. Iron isotopes provide a tracer for the influence of biological activity and oxygen in weathering processes through Earth history. Iron isotopic fractionation during weathering may have been smaller or absent in an oxygen-poor environment such as that of the early Precambrian Earth.
\end{abstract}




\section{Introduction}

Continental weathering involves the breakdown of minerals in rocks by mechanical and chemical means, the subsequent development of soils, and the transport of weathering products to the ocean via rivers. The effect of these processes on the mobility of Fe is of great interest, because of Fe's role as a micronutrient in biological systems and its potential for regulating global climate on geological timescales via natural Fe fertilization [1]. In the modern oxidizing weathering environment, the stable forms of Fe are the insoluble and generally immobile ferric species, which exist mainly as oxides $\left(\mathrm{Fe}_{2} \mathrm{O}_{3}\right)$ and hydroxides $\left[\mathrm{Fe}(\mathrm{OH})_{3}\right.$ and $\left.\mathrm{Fe}(\mathrm{OOH})\right]$ and produce the red color of many rocks and soils. Under generally oxidizing conditions, Fe is mobilized mainly by local reduction and complexation with organic ligands. These two processes have been shown to affect the isotopic composition of $\mathrm{Fe}$, concentrating the light isotope preferentially in the complexed or reduced phase $[2,3]$. The immobilizing process during weathering is the precipitation of ferrihydrite, which has been shown to concentrate isotopically-heavy Fe in precipitates from natural waters [4].

Repeated cycles of dissolution and precipitation during continental weathering may generate relatively large Fe isotope fractionations, as isotopically-heavy Fe is retained in weathered residue on continents while isotopically-light Fe is preferentially transported to the ocean in the dissolved phase. The current work reports significant natural Fe isotope fractionations in representative samples of the weathering cycle (Table 1). The data indicate that the isotopic composition of Fe delivered to the oceans and preserved in paleosols may be indicative of weathering conditions and biological activity. 
Consequently, Fe isotopic variations in the rock record may provide clues about the changing roles of oxygen and biological activity in Earth's surface geochemical cycles over geologic time.

\section{Analytical Methods}

Samples were dissolved in a heated $\left(<200^{\circ} \mathrm{C}\right)$ solution of concentrated hydrofluoric (HF), perchloric $\left(\mathrm{HClO}_{4}\right)$, and nitric acids $\left(\mathrm{HNO}_{3}\right)$. Soil samples were combusted at $600^{\circ} \mathrm{C}$ for $\sim 12$ to 20 hours in a muffle furnace to destroy organic material prior to leaching and dissolution. Selective leaches were performed on the soil samples in water and $0.5 \mathrm{~N} \mathrm{HCl}$. Approximately $10 \mathrm{ml}$ of $0.5 \mathrm{~N} \mathrm{HCl}$ or water was added to $50 \mathrm{mg}$ of precombusted soil in acid-washed $30 \mathrm{ml}$ teflon Savillax vials and then shaken at $150 \mathrm{rpm}$ for 24 hours prior to filtering through acid-washed $0.45 \mu \mathrm{m}$ Millipore Durapore ${ }^{\mathrm{TM}}$ polyvinylidene fluoride membrane filters under vacuum.

Marine carbonate sediments were weighed into acid-washed Savillax beakers and dissolved in $0.5 \mathrm{~N} \mathrm{HCl}$. The resulting solutions were capped and placed on a hot plate at low heat overnight to ensure total carbonate dissolution. The samples were subsequently placed into acid-washed polyethylene centrifuge tubes and centrifuged for 30 minutes at $4500 \mathrm{rpm}$. After the supernatant was decanted off, a single $0.5 \mathrm{~N} \mathrm{HCl}$ rinse was added to the centrifuge tube and the solution recentrifuged and decanted. There was a significant amount of detrital non-carbonate material remaining after the second centrifugation step and it is possible that this material may have contributed adsorbed Fe to the "carbonate fraction" of the sample. 
Dilute $\mathrm{HCl}$ extraction of $\mathrm{Fe}$ over a relatively long amount of time (24 hours) was used as in place of ammonium oxalate extraction to ensure complete dissolution of amorphous and short-range crystalline $\mathrm{Fe}[5,6]$. However, it is possible that goethite and hematite in the sample were partially dissolved and contributed $\mathrm{Fe}$ to the sample [6]. In $0.5 \mathrm{~N} \mathrm{HCl}$ at $25^{\circ} \mathrm{C}$, goethite and hematite dissolve 10 to 100 times slower than less crystalline oxides such as lepidocrocite and akaganeite [7]. Hence the leaching procedure is unlikely to have dissolved more than a small fraction of the goethite and hematite while completely dissolving the less crystalline and amorphous components.

Aliquots of unfiltered river water were dried under a heat lamp in a nitrogen atmosphere and partially digested in hot $6 \mathrm{~N}$ nitric acid overnight prior to bulk digestion. Stream sediment fractions were separated from the bulk sediment using the method indicated (Table 1) and then leached in aqua regia prior to Fe separation. The oxidized fraction from the Eel River was composed of rounded sand-size grains with Fe-oxide matrices surrounding lithic/mineral fragments.

Iron isotopic compositions were measured by thermal ionization mass spectrometry with $\mathrm{a}^{54} \mathrm{Fe}^{58} \mathrm{Fe}$ double spike using a VG Sector 54 multi-collector mass spectrometer. The "spike-subtracted" Fe isotope ratios were determined using an iterative technique after normalizing to ${ }^{54} \mathrm{Fe} /{ }^{56} \mathrm{Fe}[8]$. Iron in all samples was separated from matrix elements in varying normalities of $\mathrm{HNO}_{3}$ using either a single-column procedure with Eichrom's RE Spec ion exchange resin or a double-column procedure with Biorad's AG-50W-X8 cation 
exchange resin. Separated Fe $(\sim 4 \mu \mathrm{g})$ was subsequently loaded onto rhenium filaments with SpecPure aluminum, high-purity phosphoric acid, and colloidal silica $(\sim 0.02 \mu \mathrm{m}$ particle size) for mass spectrometric analysis.

During mass spectrometric analysis, the ion beam intensity of all four Fe nuclides (54, $56,57,58)$ are measured during one scan. Two other scans are used to monitor ${ }^{53} \mathrm{Cr}$ and ${ }^{60} \mathrm{Ni}$ for potential isobaric interferences at ${ }^{54} \mathrm{Cr}$ and ${ }^{58} \mathrm{Ni}$, respectively. The ${ }^{56} \mathrm{Fe}$ beam intensity varies between 1.5 and $2.5 \mathrm{~V}$ during the course of a run while the ${ }^{54} \mathrm{Fe}$ and ${ }^{58} \mathrm{Fe}$ beams average $\sim 200$ and $40 \mathrm{mV}$, respectively.

All data herein are reported in delta notation, $\nabla^{6} F e_{\text {standard }}=\frac{\square(56 / 54)_{\text {sample }}}{-(56 / 54)_{\text {standard }}} \square 1$ 最 1000 , where our standard is the Columbia River basalt, BCR-1 $\left({ }^{54} \mathrm{Fe} /{ }^{56} \mathrm{Fe}=0.0636779\right)$. The $2 \square$ error for each individual measurement $(n=1)$ is calculated using the instrumental $2 \square$ error of the $57 / 56$ ratio, where the 57 beam is the smallest of the four Fe ion beams measured. A typical TIMS run has a 57/56 standard error $<0.0080 \%$, which corresponds to a $\square^{56} \mathrm{Fe}$ error $<0.15 \%$. If the $2 \square$ errors for any given analytical run are propagated through the iterative spike subtraction algorithm, the $2 \square$ error of the $54 / 56$ ratio increases by a factor of $\sim 2$. If the $2 \square$ errors are calculated based on a weighted average scheme, the typical $2 \square$ error is $<0.20 \%$ for a sample where the number of replicates, $n$, is $\geq 2$.

Data from other TIMS studies are reported here relative to BCR-1, BCR-2, or BIR-1, all of which are assumed to have the same Fe isotope composition within $\pm 0.05 \%$ [9]. 
Multiple collector ICP-MS (MC-ICP-MS) data are expressed relative to a Columbia River basalt (or equivalently Skulan et al.'s [11] "whole-earth average”). We convert Zhu et al.'s [26] $\square^{77} \mathrm{Fe}_{\text {IRMM-014 }}$ data to $\square^{66} \mathrm{Fe}_{\text {IRMM-014 }}$ using the relation $\square^{66} \mathrm{Fe}_{\text {IRMM-014 }}=$

$0.678 \cdot \square^{77} \mathrm{Fe}_{\text {IRMM-014 }}[10]$, and then convert these data to $\square^{56} \mathrm{Fe}_{\text {whole-earth }}$ using Skulan et al.'s [11] measurement of IRMM-014 relative to their whole-earth average $(-0.11 \pm 0.07 \%$ ) Sharma et al.'s[12] MC-ICP-MS Fe isotope data, reported relative to their laboratory standard, are renormalized to BCR-2 using their measurements of IRMM-014 and BCR2.

\section{Sample locations and descriptions}

Soil samples from a marine terrace near Mendocino, California were sampled and measured in this study (Fig. 1). The mean annual precipitation in the region is $\sim 127 \mathrm{~cm}$, and the mean annual air temperature is $\sim 12^{\circ} \mathrm{C}$ [13]. The Ferncreek series (est. 300 to 400 ka [14]), in particular, consists of very deep, somewhat poorly drained soils (clayey, mixed, isomesic Plinthic Haplohumults) developed over marine sediments. The rocks upon which the Ferncreek soil is developed are part of the Coastal Belt of the Franciscan complex, and are late Cretaceous to early Tertiary in age [15]. Our sample location for the Ferncreek overlies Bachman's (1974) western unit of the Coastal Belt, a heavily deformed sequence of mudstones, interbedded sandstones and mudstones, and minor conglomerates [15]. The Ferncreek soil contains a $\sim 5 \mathrm{~cm}$ organic O-horizon (black in color), a well-developed $\sim 18 \mathrm{~cm}$ thick leached E-horizon (gray in color), and zones of iron and clay accumulation in the B horizons ( $\sim 18$ to $155 \mathrm{~cm}$ depth; orange to red in color). The lower $\mathrm{B}_{\mathrm{tv}}$ horizons ( $\sim 61$ to $155 \mathrm{~cm}$ depth) contain red iron-rich nodules, 
which may be associated with aggregations of organic carbon. The Ferncreek is generally extremely to strongly acid, with pHs between 3.9 (E horizon) and 4.9 [13].

River waters were sampled July 29 through September 24, 2000 along the coast of the Western United States and Canada (Fig. 1). The western coast of North America contributes an average of $131 \cdot 10^{6}$ tons $\mathrm{yr}^{-1}$ of suspended sediment discharge to the Pacific Ocean while the Yukon contributes a large share of the $444 \cdot 10^{6}$ tons $\mathrm{yr}^{-1}$ of suspended sediment discharge to the Bering Sea [16]. Temperature and $\mathrm{pH}$ were measured as noted in Table 2. Standard procedure was to take an aliquot of river water in a plastic beaker and measure $\mathrm{pH}$ after standardizing the meter between $\mathrm{pH} 4$ and 7 . Temperature $\left({ }^{\circ} \mathrm{C}\right)$ was measured in situ where possible and in the beaker otherwise. Most rivers were sampled near the middle; the Copper and Fraser Rivers were sampled from the bank. Stream sediments were collected from the river bank in clean polyethylene snap-top containers and double bagged in clean plastic bags.

Marine sediment core LL44-GPC3 $\left(30^{\circ} 19.9^{\prime} \mathrm{N}, 157^{\circ} 49.9^{\prime} \mathrm{W}\right.$; $5705 \mathrm{~m}$ depth) is located in the central gyre of North Pacific Ocean (Fig. 1) and is dominated by eolian input [17-21]. The pelagic clay core is 24.31 meters in length, the top $20.6 \mathrm{~m}$ of which contains a relatively complete Cenozoic record. Sedimentation rates in the core vary between 0.2 and $2 \mathrm{~m} \mathrm{Ma}^{-1}$ while mass accumulation rates are estimated to be between 8 and $137 \mathrm{~g} \mathrm{~cm}^{-}$ ${ }^{2} \mathrm{Ma}^{-1}[18]$. Iron content in the core ranges between 49 and $147 \mathrm{mg} \mathrm{Fe} \mathrm{g}^{-1}$ sediment, with significant peaks at $\sim 48.3 \mathrm{Ma}\left(147 \mathrm{mg} \mathrm{g}^{-1}\right)$ and $57.3 \mathrm{Ma}\left(129 \mathrm{mg} \mathrm{g}^{-1}\right)$ [18]. 
Carbonate sediments (nannofossil ooze) come from Deep-Sea Drilling Project Site 590, Hole 590B on the Lord Howe Rise in the southwest Pacific Ocean ( $31^{\circ} 10.02^{\prime} \mathrm{S}$, $163^{\circ} 21.51^{\prime} \mathrm{E}$; $1299 \mathrm{~m}$ water depth) $[22,23]$. Site 590 is situated on the subtropical divergence in the transitional zone between warm subtropical and temperate regions [22, 23]. The sediment is primarily nannofossil ooze but contains foraminifera-rich intervals and thin volcanic ash layers $[22,23]$. The oldest sediments cored were earliest Miocene $(\sim 24 \mathrm{Ma})$.

\section{Results}

The results of our Fe isotope measurements in six North American rivers, a soil profile from the Ferncreek soil series (Mendocino County, California), and marine sediment core samples are shown in Table 1 and Figure 2. Iron in the Ferncreek soil profile is isotopically fractionated relative to average igneous rocks $\left(\square^{56} \mathrm{Fe}=0 \%\right.$ ) by +0.5 to $+1.4 \%$, with notable differences in $\square^{56} \mathrm{Fe}$ between shallow organic-rich and deeper mineral horizons. Our interpretations of the intra-profile variations (Fig. 3), detailed below, suggest that the bulk soil has $\square^{56} \mathrm{Fe}$ of about +1 . It is most likely that the generally heavy nature of the Ferncreek soil is due to previous weathering cycles and/or diagenetic processes which have isotopically fractionated the Coastal Belt mudstones that serve as parent material for the Ferncreek. The data suggest that weathering under oxidizing conditions can generate significant Fe isotope fractionation and produces material with both elevated and decreased $\square^{56}$ Fe relative to the unweathered rock. Stream bed load fractions from the Eel and Copper Rivers, leached with aqua regia to remove Fe-bearing coatings on the sediment grains, yield leachate $\square^{56} \mathrm{Fe}$ of +0.9 to +1.8 . This result 
confirms that precipitates generated as part of the weathering-transport process can be enriched in heavy Fe [4].

The $\square^{56} \mathrm{Fe}$ values for unfiltered river water vary between -2.9 and +1.1 (Table 1). The river values cover almost the entire range of known $\square^{56} \mathrm{Fe}$ for terrestrial materials (Fig. 2). For the river waters with the highest $\mathrm{Fe}$ concentrations and high values of $\mathrm{Al} / \mathrm{Ca}$ (Table 2), the $\mathrm{Fe}$ in the sample is mainly contained in the suspended load and varies in $\square^{56} \mathrm{Fe}$ from +1.1 to -0.5 . The range of riverine ${ }^{56} \mathrm{Fe}$ is significantly larger than that reported for igneous rocks [9]. The two rivers with the lowest Fe concentration and with low $\mathrm{Al} / \mathrm{Ca}$ have $\square^{56} \mathrm{Fe}$ values of +0.6 and -2.9 , possibly approaching the isotopic composition of the dissolved load in these rivers. The most notable result is the negative value for the Klamath River sample, which is the sample with the lowest $\mathrm{Al} / \mathrm{Ca}$, the highest values of $\mathrm{Na} / \mathrm{Fe}$ and $\mathrm{Ca} / \mathrm{Fe}$, and highest ratio of dissolved $\mathrm{Fe}$ to sediment load [24]. The Klamath River sample provides evidence that the dissolved fraction of riverine Fe can be isotopically-light and strongly fractionated relative to igneous rocks [25]. In general, the river data confirm that significant $\mathrm{Fe}$ isotopic fractionation occurs in weathering processes, producing both high and low values of $\square^{56} \mathrm{Fe}$.

Four samples of deep-sea pelagic clay from the central Pacific Ocean have uniform $\square^{56} \mathrm{Fe}$ of +0.9 to $+1.1 \%$, similar to the average Ferncreek soil $\square^{56} \mathrm{Fe}$ values and different from $\square^{56} \mathrm{Fe}$ values reported for igneous rocks [9]. These samples indicate that fine-grained clastic materials on the ocean floor, which are produced during continental weathering and subsequently altered during transport and deposition, contain Fe that is isotopically 
heavy. The clay $\square^{56} \mathrm{Fe}$ values are notably higher than values in the most likely source material, Asian loess $(0.05 \pm 0.37)$ [26]. The observation of elevated $\square^{56} \mathrm{Fe}$ in pelagic clays may therefore require $\mathrm{Fe}$ isotopic fractionation during transport from continental sources or following deposition in the ocean. The $\square^{56} \mathrm{Fe}$ values of carbonate ooze from the southwest Pacific are also close to $+1 \%$, different from igneous rocks yet similar to the $\square^{56} \mathrm{Fe}$ of pelagic clays. The $\mathrm{Fe}$ measured in the carbonate oozes derives from $\mathrm{Fe}$ incorporated into the nanoskeletons by the living organisms, Fe-oxides precipitated on the exterior of the carbonate tests from the water column, and post-depositional Fe-Mn coatings on the grains. Fractionation of this Fe could occur as a result of organic Fe uptake, biotic or abiotic Fe-oxide precipitation, and/or dissolution-precipitation reactions during diagenesis. Overall, the deep sea sediment data indicate that processes operating in the marine environment affect $\mathrm{Fe}$ isotope fractionation in addition to that produced by weathering in soils.

\section{Discussion}

The observations that we consider to be critical for analyzing the behavior of $\mathrm{Fe}$ isotopes in the continental weathering cycle are: (1) intraprofile fractionation in the Ferncreek soil, (2) heavy Fe leached from stream sediments, (3) the range of $\square^{56} \mathrm{Fe}$ values found in river waters, including both heavy and light values, (4) the low $\square^{56} \mathrm{Fe}$ of the Klamath River water sample that is probably representative of the dissolved Fe, and (5) heavy Fe in the deep sea clay and carbonate ooze. Considering these observations in the context of other recently reported experimental and field studies (Fig. 2), we hypothesize that Fe isotope fractionation during weathering is produced by cycles of Fe reduction, organic-Fe 
chelation and biological cycling, and hydroxide precipitation, each of which has been documented to affect Fe isotope composition $[2,3,10,11]$.

\subsection{Fractionation of Fe isotopes by soil processes}

In general, reduction and complexation solubilize isotopically-light Fe while hydroxide precipitation immobilizes heavy Fe. This pattern has been illustrated in the field by measurements of soil exchangeable $\mathrm{Fe}$, which tends to be light $\left(\square^{66} \mathrm{Fe}=-0.85 \%\right)$ and soil Fe oxides, which are heavy $\left(\square^{56} \mathrm{Fe}=0.16 \%\right)[2]$. Biological cycling plays a role in that biologically-produced organic ligands preferentially complex isotopically light $\mathrm{Fe}$, which can then be taken up by organisms or mobilized to deeper reaches of the soil [2, 27]. As organic material decays, isotopically light Fe can be released back into the soil profile bound to organic ligands such as oxalate and siderophores [28]. The organic complexation increases the solubility of $\mathrm{Fe}^{3+}$ [29], producing a source of isotopically light, but oxidized, iron that is relatively mobile within the soil and subsequently is transported to streams (Table 1). Reductive dissolution of oxide coatings in watersaturated horizons can also contribute isotopically-light Fe to the mobile phase, albeit subject to seasonal and annual fluctuations in rainfall and, therefore, water table depth.

The complexity and general nature of processes within a soil profile are illustrated by the data from the Ferncreek soil (Fig. 3). The $\mathrm{O}$ and $\mathrm{E}$ horizons of the soil are both highly depleted in Fe and the bulk samples have relatively low $\square^{56} \mathrm{Fe}$ by comparison with the deeper B horizons which have higher Fe contents. However, the $\mathrm{HCl}$-leaches of the $\mathrm{O}$ and $\mathrm{E}$ horizons yielded heavy $\mathrm{Fe}$, whereas the $\mathrm{HCl}$-leaches of the deeper horizons yielded 
relatively light $\mathrm{Fe}$. This pattern can be understood in terms of release of light $\mathrm{Fe}$ from silicates by weathering processes in the B horizons, uptake and upward transport of this light Fe by root systems, and subsequent decay of organic matter and redistribution by soil water.

The use of Fe by plant root systems requires Fe to be organically-chelated prior to uptake $[27,30]$. In the case of grasses, for example, roots actively release "phytosiderophores" into the soil and siderophore-bound $\mathrm{Fe}$ is subsequently taken up by plant roots [27]. If light $\mathrm{Fe}$ is favored by phytosiderophores [2], then plant tissue will be isotopically lighter than the bulk soil from which it was derived. Hence the O-horizon, composed primarily of decomposed organic matter derived from surface plant material, has a bulk $\square^{56} \mathrm{Fe}$ that is $0.5 \%$ lower than the Fe in the B-horizons (Table 1; Fig. 3e). Equilibrium models of Fe speciation in soils indicate that there is essentially no free Fe ion in soil solutions [31]. According to van Hees and Lundström (2000), Fe in soil solution is primarily bound to high molecular weight organic acids with a small proportion complexed by oxalate and citrate. Thus it is highly likely that the majority of isotopically-light Fe in the O-horizon is organically bound, most likely to large organic molecules derived from the decay of surficial plant debris. The Fe-poor E-horizon also has low $\square^{56} \mathrm{Fe}$, suggesting that a large proportion of $\mathrm{Fe}$ in the E-horizon is derived from the mobile, organically-bound $\mathrm{Fe}$ transported from the O-horizon.

The $0.5 \mathrm{~N} \mathrm{HCl}$ leachates (Fig. 3) represent adsorbed Fe and oxide- or hydroxide- bound Fe with minimal silicate-bound $\mathrm{Fe}$ [5]. The Fe from the $\mathrm{HCl}$ leach is heavy in the O- and 
E-horizons, which presumably represents precipitates that incorporate the organically processed light Fe but are enriched due to fractionation associated with precipitation [4]. In the $\mathrm{B}$-horizons the $\mathrm{Fe}$ from the $\mathrm{HCl}$ leach is lighter than the bulk soil, which may represent either organically-complexed Fe not yet taken up by roots or previously processed Fe that has been transported from the O-horizon. Overall, the data illustrate that biological processes can remove isotopically light $\mathrm{Fe}$ from the soil and redeposit it at the top of the soil profile, whereupon it can be subsequently transported down in the soil profile and potentially reprocessed.

Since the Ferncreek soil is saturated to the bottom of the $\mathrm{B}_{\mathrm{tv}}$-horizon during wet months, it is also likely that reductive dissolution of Fe-hydroxide coatings observed in waterlogged soils also affects the isotopic composition of the Fe released under saturated conditions [32]. During reductive dissolution, isotopically light Fe may be released into solution, creating a mobile reservoir which is isotopically lighter than the parent material and a bulk profile that is slightly heavier than the assumed parent material. This is exactly the pattern observed in the $\mathrm{B}_{\mathrm{tv}}$-horizon, in which the $0.5 \mathrm{~N} \mathrm{HCl}$ leach is about $0.4 \%$ lighter and the bulk soil about $0.2 \%$ heavier than the assumed $+1 \%$ parent material (Fig. 3e).

\subsection{Fe isotope fractionation in the marine environment}

The data on pelagic clays suggest that processes other than those that operate in soils can cause Fe isotope fractionation. Photochemical and acid dissolution reactions during atmospheric dust transport, chemical reactions within the marine water column, or 
diagenetic processes following deposition may contribute to the observed, relatively high $\square^{56} \mathrm{Fe}$ of deep sea clays. Experimental data indicate that dissolved $\mathrm{Fe}(\mathrm{III})_{\mathrm{aq}} \mathrm{can}$ be fractionated by as much as $+2.75 \pm 0.15 \%$, relative to $\mathrm{Fe}(\mathrm{II})_{\mathrm{aq}}$ [33]. Therefore it is possible that precipitation and preferential sedimentation of a $\mathrm{Fe}(\mathrm{III})$-oxide or oxyhydroxide (such as hematite or ferrihydite) could enrich marine sediments in isotopically-heavy Fe. It is also possible that the redox environment of the deep ocean affects the isotopic composition of $\mathrm{Fe}$ deposited in deep-sea sediments. Removal from the water column under oxidizing conditions, for example, may involve chemical pathways that fractionate $\mathrm{Fe}$ isotopes in a different manner than removal processes under anoxic conditions.

Isotopic enrichment of sedimentary Fe could also occur during diagenesis, as particulate sedimentary Fe is reduced and isotopically-light Fe(II) is released into solution and redistributed within the sediment column via pore waters [3]. It has been observed that pore water Fe(II) concentrations in "enriched" horizons in some sediments reach up to $\sim 50$ times ambient $\mathrm{Fe}$ (II) concentrations [34]. Significant Fe reduction could also occur during periods of anoxia in marine bottom waters.

\subsection{Isotopic composition of riverine dissolved Fe}

Our data on river waters are not sufficient to fully characterize the $\square^{56} \mathrm{Fe}$ of riverine dissolved $\mathrm{Fe}$ but, in combination with the soil and mudrock data as well as data from recent literature, they allow us to propose a simple model. Soil data indicate that soluble

Fe tends to have relatively low $\square^{56} \mathrm{Fe}$ and that material residual from weathering tends to 
have higher $\square^{56} \mathrm{Fe}$ (Fig. 3; ref. 2). This suggests that the dissolved Fe supplied to rivers from rock weathering should have low $\square^{6} \mathrm{Fe}$. Precipitates formed in rivers also tend to be isotopically heavy (Table 2) and fractionated relative to dissolved Fe [4], so that Fe precipitation in streams tends to drive the $\square^{56} \mathrm{Fe}$ of the dissolved $\mathrm{Fe}$ to lower values. Documenting the isotopic character of riverine dissolved Fe is not straightforward due to the preponderance of $\mathrm{Fe}$ in suspended material, but our analysis of Klamath River water suggests that the dissolved load can have low $\square^{56} \mathrm{Fe}$. The relatively high $\square^{56} \mathrm{Fe}$ values of deep sea clay are also consistent with the model that weathering preferentially removes light Fe from rocks. Hence, although dissolved riverine Fe is likely to be heterogeneous, our hypothesis is that, in general, the $\square^{56} \mathrm{Fe}$ value is in the range of 0 to $-3 \%$.

\subsection{The global Fe budget}

A preliminary marine Fe isotopic budget can be assembled from the available data regarding annual Fe fluxes and their Fe isotope ratios (Fig. 4). Rivers transport 12 to 18 Tmol Fe $\mathrm{y}^{-1}$, but only about $0.026 \mathrm{Tmol}^{-1}$ is in the dissolved form [35]. Since up to $90 \%$ of the riverine dissolved Fe can be removed in estuaries, the minimum net riverine Fe flux to the oceans is about $0.003 \mathrm{Tmol}^{-1}[35,36]$. Marine hydrothermal systems [35, $37]$ and the atmosphere $[35,38]$ contribute less total $\mathrm{Fe}$ to the global ocean than rivers, but the dissolved Fe fluxes from these two sources may be similar in magnitude to the dissolved riverine flux [39, 40]. The isotopic composition of dissolved Fe from atmospheric and hydrothermal sources is uncertain. However we hypothesize that solubilization processes in aerosols during transport might fractionate Fe isotopically, preferentially dissolving light Fe. This relatively light pool may be further fractionated 
while cycling through the photic zone and during transport to and deposition in marine sediments. Dissolved hydrothermal Fe is assumed to have the isotopic composition of the fluids that have been measured at deep sea vents [12], although the uncertainty in this assumption is rather large.

The flux of diagenetic Fe from marine sediments to the ocean may also be significant [41-43]. While it is known that Fe is reduced during burial in marine sedimentary columns [34], the escape of Fe from sediments into the overlying water column correlates with and is presumably controlled by the flux of organic carbon $\left(\mathrm{C}_{\mathrm{org}}\right)$ to the sediments $[43,44]$. Diagenetic Fe fluxes of 12 to $35 \mathrm{mmol} \mathrm{Fe} \mathrm{m}^{-2} \mathrm{y}^{-1}$ are estimated for sediments receiving $\geq 1200 \mathrm{mmol} \mathrm{C} \mathrm{m}^{-2} \mathrm{y}^{-1}[43,44]$ while direct flux measurements of $\sim 18 \mathrm{mmol} \mathrm{Fe}$ $\mathrm{m}^{-2} \mathrm{y}^{-1}$ are observed in Black Sea shelf sediments [45]. Diagenetic Fe reduction is likely to be restricted to coastal regions and enclosed sedimentary basins which can have $\mathrm{C}_{\text {org }}$ accumulation rates of 500 to $4000 \mathrm{mmol} \mathrm{C} \mathrm{m}^{-2} \mathrm{y}^{-1}[42,46]$. Given a coastal ocean surface area of $3 \cdot 10^{13} \mathrm{~m}^{2}$ ( 0 to $200 \mathrm{~m}$ depth) [47], these numbers suggest that the diagenetic Fe flux could be as high as 0.35 to $1 \mathrm{Tmol} \mathrm{Fe}^{-1}$, much larger than the other sources of marine dissolved Fe.

The influence of diagenetic Fe on the global Fe cycle depends on the proportion of diagenetic Fe that survives in the water column. Considering the low solubility of Fe in the modern ocean $\left(0.1\right.$ to $\left.0.6 \mathrm{nmol} \mathrm{L}^{-1}\right)$ [48], the residence time of dissolved diagenetic $\mathrm{Fe}$ in the coastal oceans is approximately 1 day if the fluxes are as high as we have estimated. After considering the small amount of diagenetically-released Fe that survives 
removal from the water column by reoxidation and precipitation, our estimated diagenetic Fe flux becomes of similar magnitude to the other dissolved Fe fluxes we have considered in the modern Fe cycle (Fig. 5). The flux of diagenetic Fe to the open ocean from coastal areas is therefore highly uncertain, but could be significant (if not large) in comparison to the other fluxes. We tentatively estimate that the diagenetic Fe flux is similar in magnitude to the other dissolved Fe fluxes we have considered (Fig. 4). The diagenetic Fe flux may prove particularly important during regional marine or global anoxic events, when increased preservation of dissolved Fe in the water column enhances the flux of diagenetic Fe that reaches the deep ocean.

The steady state $\square^{56} \mathrm{Fe}$ of dissolved Fe in the oceans is described approximately by:

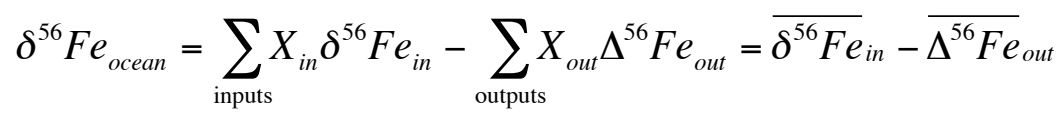

where $X_{\text {in }}$ and $X_{\text {out }}$ are the molar fractions of the various input and output fluxes. The term $\Delta^{56} F e_{\text {out }}$ represents the fractionation factors, of the form $\square^{56} F e_{\text {out }}=1000 \ln \left(\square_{\text {out }}\right)$, associated with removal of dissolved Fe from the water column. We estimate the $\square^{56} \mathrm{Fe}$ of inputs to the ocean to be in the range of 0 to $-3 \%$ and the fractionation due to the dominant removal process, chemical precipitation, to be between 0 and $+2 \%$.

Consequently the $\square^{56} \mathrm{Fe}$ of dissolved $\mathrm{Fe}$ in an oxygenated ocean should vary between 0 and perhaps $-4 \%$ (Fig. 4). This inference is consistent with available measurements on marine Fe-Mn nodules $[3,9]$. The $\square^{56}$ Fe values in a 6 Ma record from an Atlantic Ocean Fe-Mn crust [26] are in the range 0.05 to $-0.87 \%$ when appropriately normalized. These 
values are presumably at least $1 \%$ heavier than the dissolved marine Fe source as a result of fractionation during Fe precipitation.

The isotopic composition of dissolved Fe in the oceans is highly susceptible to changes in the fluxes into and out of the oceans [36] and hence should be both spatially and temporally variable over geologic time. Changes in the dissolved riverine, atmospheric, hydrothermal, and diagenetic Fe fluxes affect the $\square^{56} \mathrm{Fe}$ of dissolved marine Fe. The relative magnitudes of the input fluxes may be affected by: increased hydrothermal activity at mid-ocean ridges; increased dust flux or dust mineralogy due to glaciation, changing wind patterns or weathering mode at dust sources; or increased riverine flux caused by tectonic uplift, increased weathering rate, or alterations in the oxidation state of the Earth's surface.

\subsection{Implications for paleo-environment}

Earth's surface conditions associated with weathering should determine the isotopic composition of dissolved riverine Fe and, ultimately, the isotopic composition of the dissolved $\mathrm{Fe}$ in the oceans. Mobilization of Fe in weathering environments depends on the local redox state and the amount of organic material present to complex Fe. Under modern surface conditions, with a highly-oxygenated atmosphere, active continental biosphere, and dominantly oxidizing oceans with circumneutral $\mathrm{pH}$, only a small fraction of the protolith Fe is removed in solution during weathering, while an even smaller fraction exists in rivers and the ocean in the dissolved form. Hence the isotopes of dissolved $\mathrm{Fe}$ in rivers and the ocean can be highly fractionated and generally light, 
producing isotopically-heavy soils and sediments which require multiple cycles of dissolution and precipitation.

Iron is far more soluble and hence mobile under reducing conditions than under oxidizing conditions. Reducing conditions decrease the number of chemical transformations that must occur in order to leach Fe from the protolith during weathering, and significantly increase the fraction of $\mathrm{Fe}$ that is leached and available to be transported in solution to the oceans. Thus, isotopic fractionation may be less pronounced under reducing conditions than under oxidizing conditions. Similarly, the absence of plants would remove an important mechanism for $\mathrm{Fe}$ isotope fractionation and tend to reduce the magnitude of $\mathrm{Fe}$ isotopic variations in the Earth's surface environment.

In the marine environment, changes in the levels of oxygen and biological productivity may affect the isotopic composition of dissolved Fe. Highly oxygenated conditions favor the particulate phases of $\mathrm{Fe}(\mathrm{III})$ while less oxygenated environments support $\mathrm{Fe}(\mathrm{II})$ in the dissolved phase. Precipitation of Fe(II) may produce much less isotopic fractionation than precipitation of $\mathrm{Fe}(\mathrm{III})$. Biological activity is responsible for the existence of organic ligands in the ocean. A reduction of marine productivity should decrease the activity of organic ligands in the water column, and thus change the isotopic composition of marine dissolved $\mathrm{Fe}$ as both biological uptake and organic complexation wane.

Prior to $\sim 2.5$ billion years ago, the Earth's atmosphere is believed to have been generally reducing, containing little free oxygen [49]. Also during this period, there was little or no 
active biosphere at the Earth's surface because the ultraviolet-shielding ozone layer in the upper atmosphere was not yet developed. The reducing conditions at the Earth's surface would have increased the solubility and mobility of Fe, resulting in less chemical processing during Fe transport to the ocean and producing a proportionally larger marine Fe reservoir that is isotopically similar to the rocks being weathered [9]. Hence oxygenpoor, biologically-inactive surface conditions should result in less isotopic fractionation during weathering than oxygen-rich, biologically-active conditions. Although at present there are insufficient data to properly address this issue, the limited range of $\square^{56} \mathrm{Fe}$ in Archean banded Fe formation sediments (Fig. 2) support the inference that Fe isotopic fractionation is affected by the oxidation state at the Earth's surface. With continuing work on characterizing isotopic fractionation in the global Fe cycle, Fe isotopes may help in identifying past global changes in surface and marine oxidation state and biological activity.

\section{Conclusions}

Based on our measurements, we conclude that the net effect of continental weathering processes is to mobilize small amounts of isotopically-light Fe into an "exchangeable", or dissolved form. This isotopically-light $\mathrm{Fe}$ is subsequently transported by rivers in solution to the ocean, leaving relatively heavy Fe oxides and oxyhydroxides in soils and as secondary Fe-coatings on stream sediments. Cycling within soils produces both isotopically light and heavy Fe. Under the oxidizing conditions that characterize the modern Earth surface environment, dissolved Fe in the oceans should be relatively light $\left(\square^{56} \mathrm{Fe}=0\right.$ to -4$)$, but variable due to its short residence time. Strongly weathered 
materials that have undergone a large amount of Fe loss should contain heavy Fe. The isotopic distinction between marine dissolved Fe and weathering residues would have been smaller in the geologic past when Earth surface conditions were reducing. A major uncertainty in the modern global Fe cycle is the magnitude and isotopic composition of the flux of diagenetic Fe from sediments to the oceans. Relatively high values of $\Delta^{56} \mathrm{Fe}$ measured in fine-grained deep sea sediments suggest that diagenesis may be important in determining the Fe isotopic composition of both mudrocks and the oceans. 


\section{Acknowledgements}

This work was partially supported by a NASA ESS Graduate Fellowship to MSF and by NSF grant EAR9909639. Major funding was provided by the Director, Office of Science, Basic Energy Sciences, Chemical Sciences, Biosciences, and Geosciences Division of the U.S. Department of Energy under Contract No. DeAC03-76SF00098. Samples of core LL44-GPC3 were provided by Dr. Frank Kyte (UCLA). Tom Owens helped with mass spectrometric analyses. The authors would especially like to thank Ryan Petterson for assistance with river sampling during the summer of 2000 and Ron Amundson for advice and help with soil sampling.

Correspondence and Requests for materials should be addressed to:

*University of California, Department of Earth and Planetary Science, 307 McCone Hall, Berkeley, CA 94720-4767. E-mail: mfantle@eps.berkeley.edu, Telephone: 510.642.9116, Fax: 510.642.9520. 


\section{References}

[1] J.H. Martin, Glacial-interglacial $\mathrm{CO}_{2}$ change: The iron hypothesis, Paleoceanography 5(1), 1-13, 1990.

[2] S.L. Brantley, L. Liermann and T.D. Bullen, Fractionation of Fe isotopes by soil microbes and organic acids, Geology 29(6), 535-538, 2001.

[3] B.L. Beard, C.M. Johnson, L. Cox, H. Sun, K.H. Nealson and C. Aguilar, Iron isotope biosignatures, Science 285(5435), 1889-1892, 1999.

[4] T.D. Bullen, A.F. White, C.W. Childs, D.V. Vivit and M.S. Schulz, Demonstration of significant abiotic iron isotope fractionation in nature, Geology 29(8), 699-702, 2001.

[5] R.A. Sutherland, Comparison between non-residual Al, $\mathrm{Co}, \mathrm{Cu}, \mathrm{Fe}, \mathrm{Mn}, \mathrm{Ni}, \mathrm{Pb}$ and $\mathrm{Zn}$ released by a three-step sequential extraction procedure and a dilute hydrochloric acid leach for soil and road deposited sediment, Applied Geochemistry 17(4), 353-365, 2002.

[6] R.J. Heck and A.R. Mermut, Mechanisms and rates of iron dissolution from Brazilian Plinthustalfs by dilute hydrochloric and ascorbic acids, Soil Science 164(4), 242-251, 1999.

[7] P.S. Sidhu, R.J. Gilkes, R.M. Cornell, A.M. Posner and J.P. Quirk, Dissolution of Iron-Oxides and Oxyhydroxides in Hydrochloric and Perchloric Acids, Clays and Clay Minerals 29(4), 269-276, 1981.

[8] T.M. Johnson, M.J. Herbel, T.D. Bullen and P.T. Zawislanski, Selenium isotope ratios as indicators of selenium sources and oxyanion reduction, Geochimica Et Cosmochimica Acta 63(18), 2775-2783, 1999.

[9] B.L. Beard, C.M. Johnson, J.L. Skulan, K.H. Nealson, L. Cox and H. Sun, Application of $\mathrm{Fe}$ isotopes to tracing the geochemical and biological cycling of Fe, Chemical Geology 195, 87-117, 2003.

[10] A. Matthews, X.-K. Zhu and K. O'Nions, Kinetic iron stable isotope fractionation between iron (-II) and (-III) complexes in solution, Earth and Planetary Science Letters 192, 81-92, 2001.

[11] J.L. Skulan, B.L. Beard and C.M. Johnson, Kinetic and equilibrium Fe isotope fractionation between aqueous $\mathrm{Fe}(\mathrm{III})$ and hematite, Geochimica et Cosmochimica Acta 66(17), 2995-3015, 2002.

[12] M. Sharma, M. Polizzotto and A.D. Anbar, Iron isotopes in hot springs along the Juan de Fuca ridge, Earth and Planetary Science Letters 6036, 1-13, 2001.

[13] J. Rittiman, Carl A. and T. Thorson, Soil Survey of Mendocino County, California, Western Part, 2003 (July 11), 1998, http://www.ca.nrcs.usda.gov/mlra02/wmendo/.

[14] R. Amundson, Relative marine terrace ages of Mendocino soil chronosequence, M.S. Fantle, ed., Berkeley, 2003.

[15] S.B. Bachman, Sedimentation and margin tectonics of the Coastal Belt Franciscan, Mendocino Coast, northern California, Doctoral dissertation, University of California, 1979. 
[16] J.D. Milliman and R.H. Meade, World-Wide Delivery of River Sediment to the Oceans, Journal of Geology 91(1), 1-21, 1983.

[17] B.H. Corliss and C.D. Hollister, A paleoenvironmental model for Cenozoic sedimentation in the central North Pacific, in: The Ocean Floor, R.A. Scrutton and M. Talwani, eds., pp. 277-304, Wiley \& Sons, 1982.

[18] F.T. Kyte, M. Leinen, G.R. Heath and L. Zhou, Cenozoic Sedimentation History of the Central North Pacific - Inferences from the Elemental Geochemistry of Core L144-Gpc3, Geochimica Et Cosmochimica Acta 57(8), 1719-1740, 1993.

[19] M. Leinen and G.R. Heath, Sedimentary Indicators of Atmospheric Activity in the Northern Hemisphere During the Cenozoic, Palaeogeography Palaeoclimatology Palaeoecology 36(1-2), 1-21, 1981.

[20] D.K. Rea and T.R. Janecek, Late Cenozoic Changes in Atmospheric Circulation Deduced from North Pacific Eolian Sediments, Marine Geology 49(1-2), 149167, 1982.

[21] T.R. Janecek and D.K. Rea, Eolian Deposition in the Northeast Pacific-Ocean Cenozoic History of Atmospheric Circulation, Geological Society of America Bulletin 94(6), 730-738, 1983.

[22] J.P. Kennett, C.C. von der Borch, P.A. Baker, C.E. Barton, A. Boersma, J.P. Caulet, W.C. Dudley, Jr, J.V. Gardner, D.G. Jenkins, W.H. Lohman, E. Martini, R.B. Merrill, R.H. Morin, C.S. Nelson, C. Robert, M.S. Srinivasan, R. Stein and A. Takeuchi, Introduction and objectives, techniques, and explanatory notes, in: Initial reports of the Deep Sea Drilling Project covering Leg 90 of the cruises of the drilling vessel Glomar Challenger; Noumea, New Caledonia, to Wellington, New Zealand, December 1982-January 1983; Part 1, J.H. Blakeslee, ed. 90, pp. 316, U.S. Govt. Printing Office, Washington, 1986.

[23] J.P. Kennett, C.C. von der Borch, P.A. Baker, C.E. Barton, A. Boersma, J.P. Caulet, W.C. Dudley, Jr., J.V. Gardner, D.G. Jenkins, W.H. Lohman, E. Martini, R.B. Merrill, R.H. Morin, C.S. Nelson, C. Robert, M.S. Srinivasan, R. Stein and A. Takeuchi, Site 590: Lord Howe Rise, $31^{\circ} \mathrm{S}$, in: Initial reports of the Deep Sea Drilling Project covering Leg 90 of the cruises of the drilling vessel Glomar Challenger; Noumea, New Caledonia, to Wellington, New Zealand, December 1982-January 1983; Part 1, J.H. Blakeslee, ed. 90, pp. 263-376, U.S. Govt. Printing Office, Washington, 1986.

[24] U.S.G.S., Water-Quality Data for USA, 2002 (December), http://waterdata.usgs.gov/nwis/qw.

[25] E.R. Sholkovitz, Chemical evolution of rare earth elements: fractionation between colloidal and solution phases of filtered river water, Earth and Planetary Science Letters 114, 77 - 84, 1992.

[26] X. Zhu, K. O'Nions, Y. Guo and B.C. Reynolds, Secular variation of iron isotopes in North Atlantic Deep Water, Science 287, 2000-2002, 2000.

[27] R. Hell and U.W. Stephan, Iron uptake, trafficking and homeostasis in plants, Planta 216(4), 541-551, 2003.

[28] G. Sposito, The chemistry of soils, xii, 277 pp., Oxford University Press, New York, 1989. 
[29] F.J. Millero, Solubility of Fe(III) in seawater, Earth and Planetary Science Letters 154(1-4), 323-329, 1998.

[30] H. Siebner-Freibach, Y. Hadar and Y. Chen, Siderophores sorbed on Camontmorillonite as an iron source for plants, Plant and Soil 251(1), 115-124, 2003.

[31] P.A.W. van Hees and U.S. Lundstrom, Equilibrium models of aluminium and iron complexation with different organic acids in soil solution, Geoderma 94(2-4), 201-221, 2000.

[32] F. Favre, D. Tessier, M. Abdelmoula, J.M. Genin, W.P. Gates and P. Boivin, Iron reduction and changes in cation exchange capacity in intermittently waterlogged soil, European Journal of Soil Science 53(2), 175-183, 2002.

[33] C.M. Johnson, J.L. Skulan, B.L. Beard, H. Sun, K.H. Nealson and P.S. Braterman, Isotopic fractionation between $\mathrm{Fe}(\mathrm{III})$ and $\mathrm{Fe}(\mathrm{II})$ in aqueous solutions, Earth and Planetary Science Letters 195(1-2), 141-153, 2002.

[34] I. Konig, M. Haeckel, M. Drodt, E. Suess and A.X. Trautwein, Reactive Fe(II) layers in deep-sea sediments, Geochimica Et Cosmochimica Acta 63(10), 1517$1526,1999$.

[35] S.W. Poulton and R. Raiswell, The low-temperature geochemical cycle of iron: From continental fluxes to marine sediment deposition, American Journal of Science 302(9), 774-805, 2002.

[36] H.J.W. de Baar and J.T.M. de Jong, Distributions, Sources and Sinks of Iron in Seawater, in: The biogeochemistry of iron in seawater, D.R. Turner and K.A. Hunter, eds., IUPAC series on analytical and physical chemistry of environmental systems 7, pp. 123-253, J. Wiley, Chichester ; New York, 2001.

[37] H. Elderfield and A. Schultz, Mid-Ocean Ridge Hydrothermal Fluxes and the Chemical Composition of the Ocean, Annual Review of Earth and Planetary Sciences 24, 191-224, 1996.

[38] T.D. Jickles and L.J. Spokes, Atmospheric Iron Inputs to the Oceans, in: The biogeochemistry of iron in seawater, D.R. Turner and K.A. Hunter, eds., IUPAC series on analytical and physical chemistry of environmental systems 7, pp. 85121, J. Wiley, Chichester ; New York, 2001.

[39] I.Y. Fung, S.K. Meyn, I. Tegen, S.C. Doney, J.G. John and J.K.B. Bishop, Iron supply and demand in the upper ocean, Global Biogeochemical Cycles 14(1), 281-295, 2000.

[40] J.K. Moore, S.C. Doney, D.M. Glover and I.Y. Fung, Iron cycling and nutrientlimitation patterns in surface waters of the World Ocean, Deep-Sea Research Part II - Topical Studies in Oceanography 49(1-3), 463-507, 2002.

[41] D.J. Mackey, J.E. O'Sullivan and R.J. Watson, Iron in the western Pacific: a riverine or hydrothermal source for iron in the Equatorial Undercurrent?, DeepSea Research Part I-Oceanographic Research Papers 49(5), 877-893, 2002.

[42] K.S. Johnson, F.P. Chavez and G.E. Friederich, Continental-shelf sediment as a primary source of iron for coastal phytoplankton, Nature 398(6729), 697-700, 1999. 
[43] J.W.M. Wijsman, P.M.J. Herman, J.J. Middelburg and K. Soetaert, A model for early diagenetic processes in sediments of the continental shelf of the Black Sea, Estuarine Coastal and Shelf Science 54(3), 403-421, 2002.

[44] J.W.M. Wijsman, J.J. Middelburg and C.H.R. Heip, Reactive iron in Black Sea Sediments: implications for iron cycling, Marine Geology 172(3-4), 167-180, 2001.

[45] J. Friedrich, C. Dinkel, G. Friedl, N. Pimenov, J. Wijsman, M.T. Gomoiu, A. Cociasu, L. Popa and B. Wehrli, Benthic nutrient cycling and diagenetic pathways in the north-western Black Sea, Estuarine Coastal and Shelf Science 54(3), 369383, 2002.

[46] J.R. Schwalbach and D.S. Gorsline, Holocene Sediment Budgets for the Basins of the California Continental Borderland, Journal of Sedimentary Petrology 55(6), 829-842, 1985.

[47] D.L. Inman and C.E. Nordstrom, On the tectonic and morphologic classification of coasts, The Journal of Geology 79(1), 1-21, 1971.

[48] T.D. Waite, Thermodynamics of the Iron System in Seawater, in: The biogeochemistry of iron in seawater, D.R. Turner and K.A. Hunter, eds., IUPAC series on analytical and physical chemistry of environmental systems 7, pp. 291342, J. Wiley, Chichester ; New York, 2001.

[49] J.F. Kasting, Earth's Early Atmosphere, Science 259(5097), 920-926, 1993.

[50] C. Klein and C.S. Hurlbut, Jr., Manual of Mineralogy, 681 pp., JohnWIley \& Sons, Inc., New York, 1993.

[51] J.I. Drever, The geochemistry of natural waters, x, 437 pp., Prentice Hall, Englewood Cliffs, N.J., 1988.

[52] M.S. Fantle, Metal fractionation and the role of colloids in transport in the Clark's Fork of the Yellowstone River watershed, Senior honors thesis, Dartmouth College, 1997. 
Table 1 - Measured Fe isotopic composition in continental iron cycle.

\author{
Sample measured \\ Mendocino, CA marine terrace soil \\ Bulk Fe \\ O horizon \\ E horizon \\ Btv horizon \\ Bctv horizon \\ Leachable Fe \\ O horizon \\ E horizon \\ Btv horizon \\ Bctv horizon \\ Total river water \\ Copper River (Alaska) \\ Yukon River (Alaska) \\ Fraser River (British Columbia) \\ Skagit River (Washington) \\ Russian River (California) \\ Klamath River (California) \\ Stream sediments \\ Eel River \\ Magnetic fraction \\ Oxidized fraction \\ Copper River \\ Magnetic fraction \\ Marine core $\left(30^{\circ} 19^{\prime} \mathrm{N}, 157^{\circ} 49.9^{\prime} \mathrm{W}\right)^{3}$ \\ LL44-GPC3, $5707 \mathrm{~m}$ depth \\ $0.25 \mathrm{~m}$ depth \\ $2.22 \mathrm{~m}$ \\ $6.36 \mathrm{~m}$ \\ $12.09 \mathrm{~m}$ \\ DSDP core $\left(31^{\circ} 10.02^{\prime} S, 163^{\circ} 21.51^{\prime} \mathrm{E}\right)$ \\ Hole 590B, 1299 m depth \\ 590B-12-6 \\ 590B-47-4 \\ Bulk rocks and minerals \\ BCR-1 (Columbia River basalt) \\ Amphibolite (Swiss Alps) \\ Ferrihydrite (Montana) \\ Chalcopyrite (Finn) ${ }^{4}$ \\ Sphalerite (Finn) ${ }^{4}$
}

$\underset{\% o}{\square^{56} \mathrm{Fe}_{\text {BCR-1 }}} \stackrel{2 \square^{1}}{2} \mathrm{n}$

Depth from surface

(cm)

-7 to 0
0 to 16
45 to 67
106 to $128+$
-7 to 0
0 to 16
45 to 67
106 to $128+$

$[\mathrm{Fe}]_{\text {bulk }}(\mathrm{ppm})^{2}$

21.960

14.012

4.214

0.422

0.177

0.064

Separation method

$\begin{gathered}\text { Franz } \\ \text { Hand-pick }\end{gathered}$
Hand-magnet
Age (Ma) ${ }^{3}$
0.14
0.94
7.6
38.5

Age (Ma)

4.14
13.6

13.6

Note

USGS rock

standard

Acid mine drainage

Hydrothermal

Hydrothermal

$\begin{array}{lll}0.70 & 0.16 & 2 \\ 0.50 & 0.13 & 2 \\ 1.24 & 0.05 & 5 \\ 1.14 & 0.04 & 6 \\ & & \\ 1.28 & 0.11 & 2 \\ 1.43 & 0.09 & 2 \\ 0.58 & 0.13 & 2 \\ 0.95 & 0.09 & 2\end{array}$

$\begin{array}{lll}0.48 & 0.09 & 2\end{array}$

$\begin{array}{lll}1.14 & 0.13 & 2\end{array}$

$\begin{array}{lll}-0.51 & 0.10 & 2\end{array}$

$\begin{array}{lll}0.34 & 0.07 & 2\end{array}$

$\begin{array}{lll}0.62 & 0.08 & 2\end{array}$

$\begin{array}{lll}-3.46 & 0.17 \quad 2\end{array}$ 
$12 \square$ error calculated from the instrumental standard error of the ${ }^{57} \mathrm{Fe} /{ }^{56} \mathrm{Fe}$ ratio.

2 Concentrations measured by isotope dilution thermal ionization mass spectrometry.

3 Pelagic clay samples from F. Kyte (UCLA); depths and ages from Kyte et al. (1993) [18].

4 "Finn" hydrothermal chimney sample courtesy of D. Kelley (UW). 
Table 2 - Molar elemental ratios $(\mathrm{mol} / \mathrm{mol})$ and relative dissolved $\mathrm{Fe}$ in various natural samples.

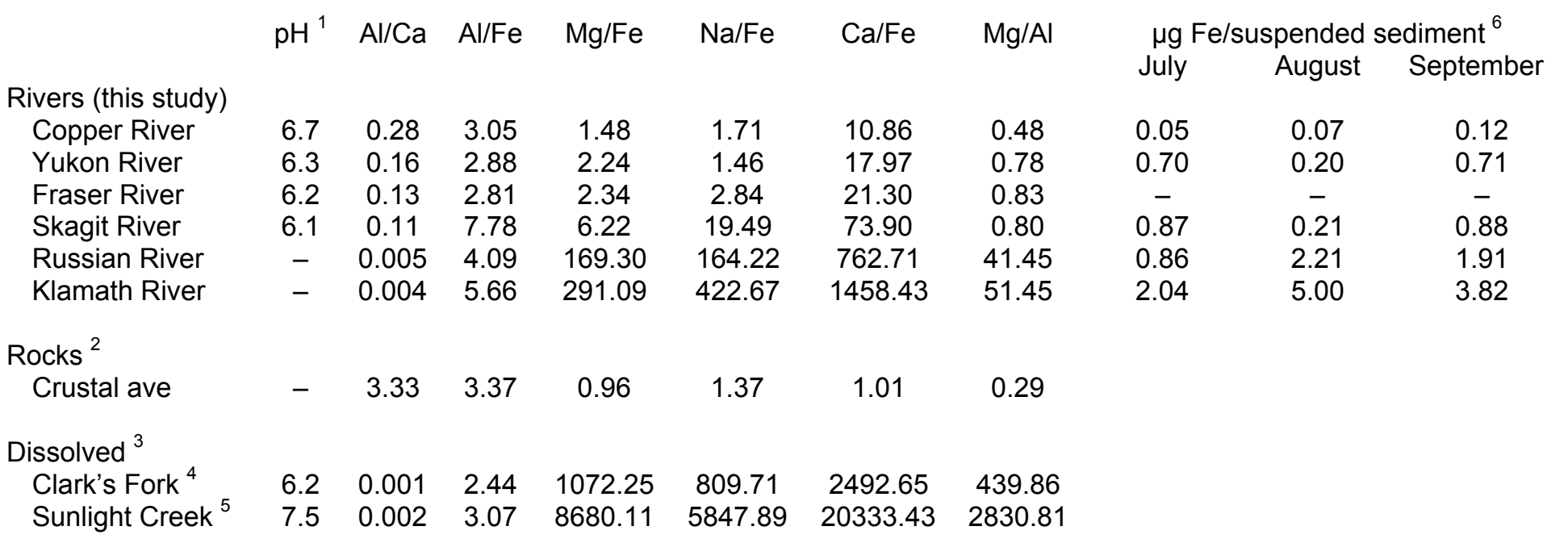

1 Measured in the field during sampling (prior to acidification). The $\mathrm{pH}$ meter broke in the field while sampling the California rivers, so there are no $\mathrm{pH}$ data available for these rivers.

${ }^{2}$ From Klein and Hurlbut (1993) and Drever (1988) [50, 51].

${ }^{3}$ River waters filtered through $0.45 \mu \mathrm{m}$ filter in the Clark's Fork of the Yellowstone River watershed, Montana [52].

${ }_{5}^{4}$ At this location, river has drained Absaroka volcanics, Beartooth granite, and carbonate terrains.

5 Drains primarily volcanic and carbonate terrain.

${ }^{6}$ Data refer to dissolved $(<0.45 \mu \mathrm{m}) \mathrm{Fe}\left(\mu \mathrm{g} \mathrm{L}^{-1}\right)$ normalized by suspended sediment $\left(\mathrm{mg} \mathrm{L}^{-1}\right)$ in the five U.S. rivers. The data making up the plot are compiled from the United States Geological Survey (USGS) Water Quality database

(http://waterdata.usgs.gov/nwis/qw). Each river contains a monthly record between 41 and 47 years in length and the results presented herein are averages of those records where both dissolved Fe and suspended measurements were made at the same time. 


\section{Figure Legends}

Figure 1 - Sample location map for six North American rivers $(\bullet)$, marine core LL44GPC3 and DSDP core 590B $(\diamond)$, and the Ferncreek soil series ( $\square$ ) whose isotopic compositions are measured in this study.

Figure 2 - Summary of iron cycle related Fe isotope measurements from this study ( $\square$ ) and recent literature. Delta values are expressed relative to a rock standard, such as BCR-1 (Columbia River basalt) or BIR-1 (Icelandic basalt). TIMS analyses by other authors $(\square \diamond \diamond)$ are indicated, as are converted data from multiple-collector inductivelycoupled plasma analyses (MC-ICP-MS) $(\boldsymbol{\Delta} \triangle)$. The shaded region between $\sim+0.3$ and $-0.3 \%$ represents the approximate range of $\square^{56} \mathrm{Fe}$ measured in igneous rocks to date (by TIMS).

Figure 3 - Chemical characteristics of measured soil profile from the Ferncreek soil series (Mendocino, CA). (a) Loss on ignition (LOI) represents that difference in weight of a given soil sample after combustion at $600^{\circ} \mathrm{C}$ for $\sim 12$ hours and is assumed to signify the amount of organic carbon present in the sample. Iron concentrations (mass Fe per mass soil) in the measured horizons are noted for (b) the bulk soil (\%), (c) the $0.5 \mathrm{~N} \mathrm{HCl}$ leach (ppm), and (d) the double deionized water leach (ppb), as measured by ICP-MS. The Fe isotopic composition $\left(\square^{56} \mathrm{Fe}\right.$ relative to BCR-1) of each horizon is shown in (e). Also indicated is a simplified soil profile which denotes the location of the measured horizons, from the uppermost $\mathrm{O}$ horizon (black) down to the lowermost $\mathrm{B}_{\mathrm{ctv}}$ horizon (cross-hatched). Note that the water table fluctuates seasonally so that the $\mathrm{B}_{\mathrm{ctv}}$ horizon is saturated in the winter and mostly dry in the summer.

Figure 4 - Two-box model of the ocean system, indicating total and dissolved Fe fluxes for the three primary inputs to the ocean and estimated sedimentary and reduction Fe fluxes. At steady state, given a total Fe input to the global ocean between 12.8 and 18.7 Tmol Fe $\mathrm{y}^{-1}$, we estimate an average global Fe sedimentation flux of 40 to $50 \mathrm{mmol} \mathrm{Fe} \mathrm{m}{ }^{-}$ ${ }^{2} \mathrm{y}^{-1}$. The notation $\square_{\text {precip }}$ refers to the difference in isotopic composition between $\mathrm{Fe}$ in solution and precipitated Fe, where $\square_{\text {precip }} \square 1000 \ln \left(\square_{\text {precip }}\right)$. Iron isotope compositions $\left(\square^{56} \mathrm{Fe}\right.$, relative to BCR-1) for components of the model are indicated in bold. The $\square^{56} \mathrm{Fe}$ values for riverine $\mathrm{Fe}$ are from the current study. The $\square^{56} \mathrm{Fe}$ values for atmospheric Fe (relative to Skulan et al.'s (2002) whole-earth average) are converted from measurements of Chinese loess by Zhu et al. (2000). The $\square^{56} \mathrm{Fe}$ values (relative to BCR-2) for hydrothermal input are converted from Sharma et al.'s (2001) $\square^{56} \mathrm{Fe}$ measurements of hydrothermal fluids, IRMM-014, and BCR-2. We calculate that $\square^{56} \mathrm{Fe}_{\mathrm{BCR}-2} \approx \square^{56} \mathrm{Fe}_{\text {whole- }}$ earth [11] and assume $\square^{56} \mathrm{Fe}_{\mathrm{BCR}-1}=\square^{56} \mathrm{Fe}_{\mathrm{BCR}-2}$. 


\section{Figures}

Figure 1

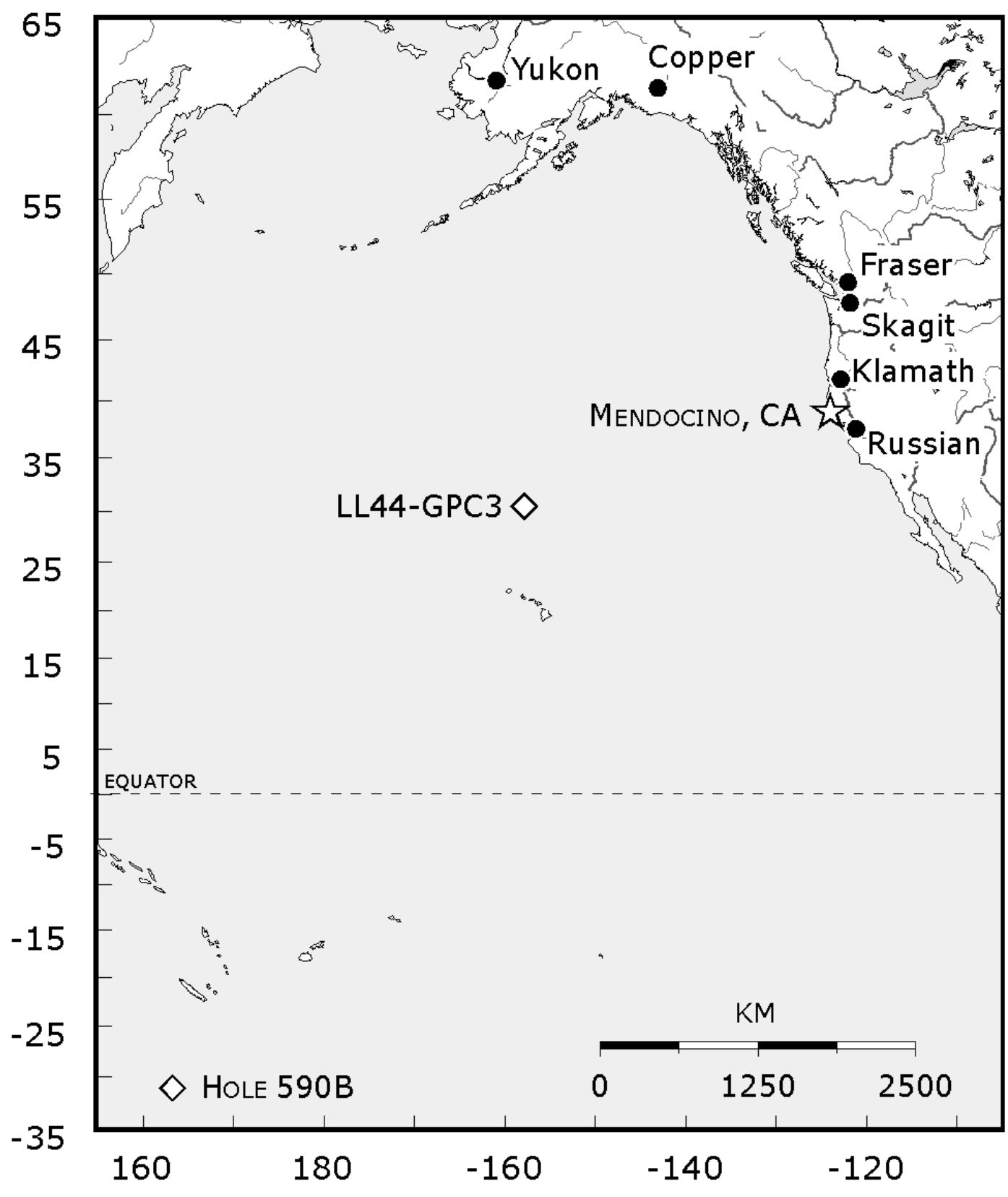


Figure 2

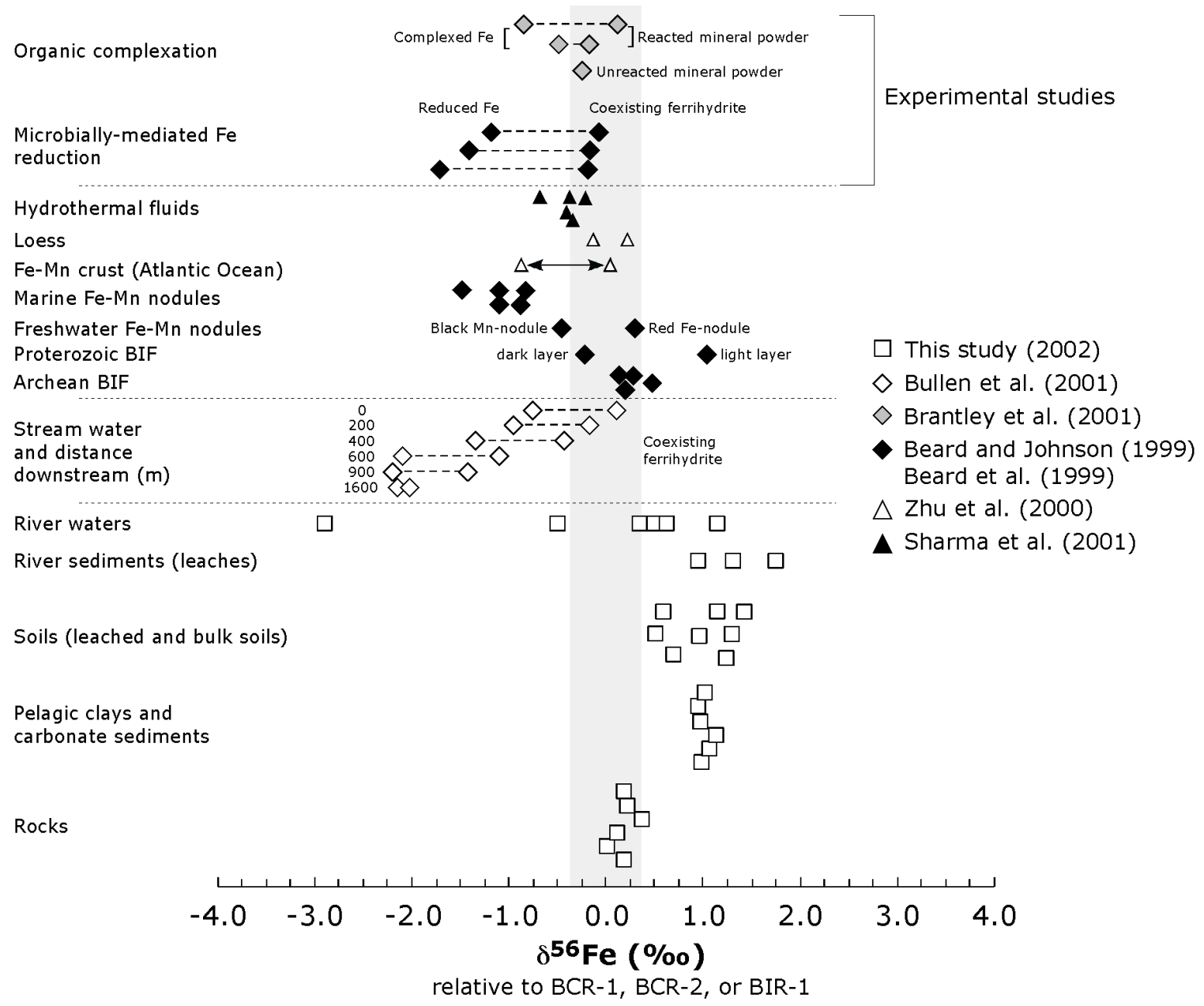


Figure 3
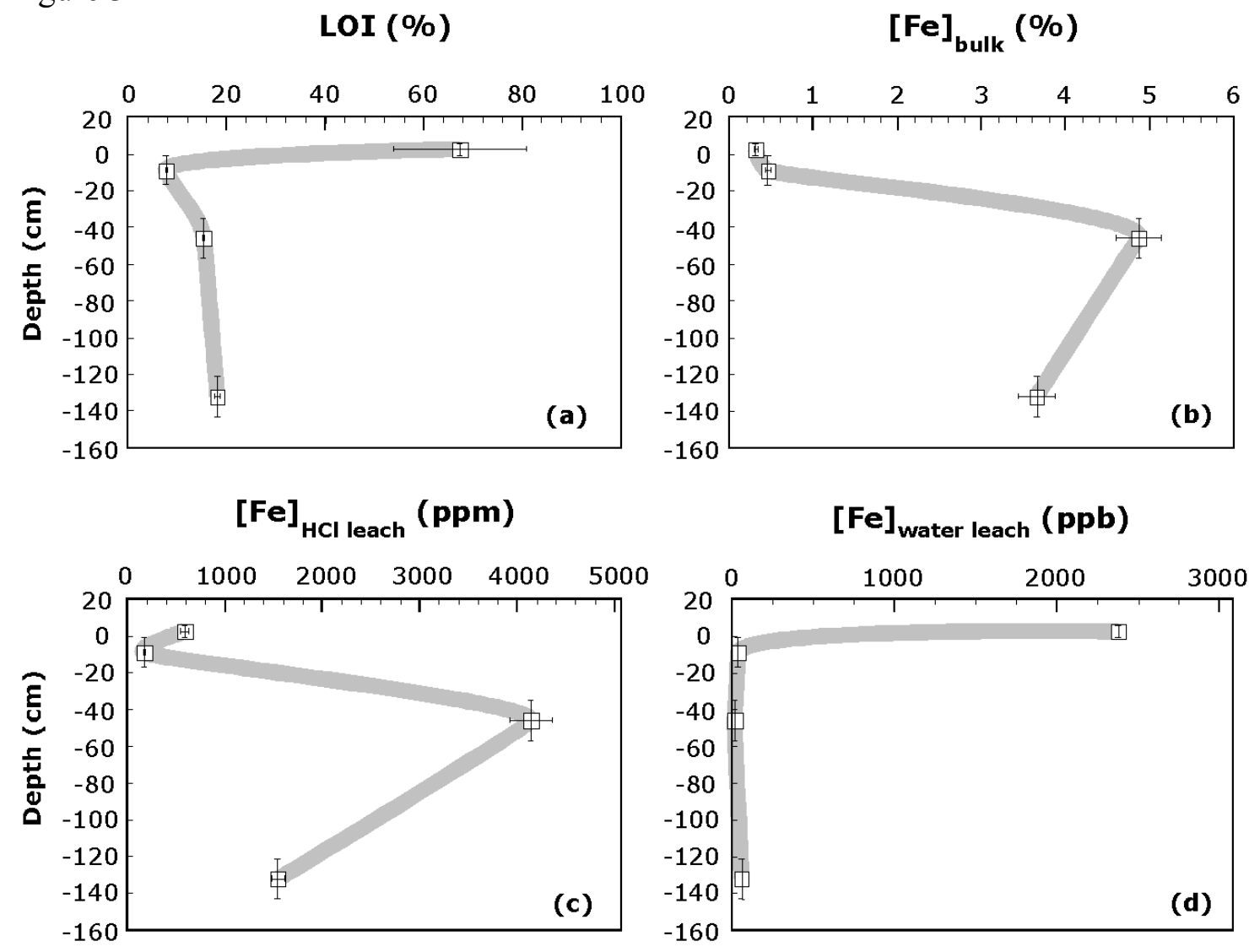

\section{¿56Fe (\%o)}

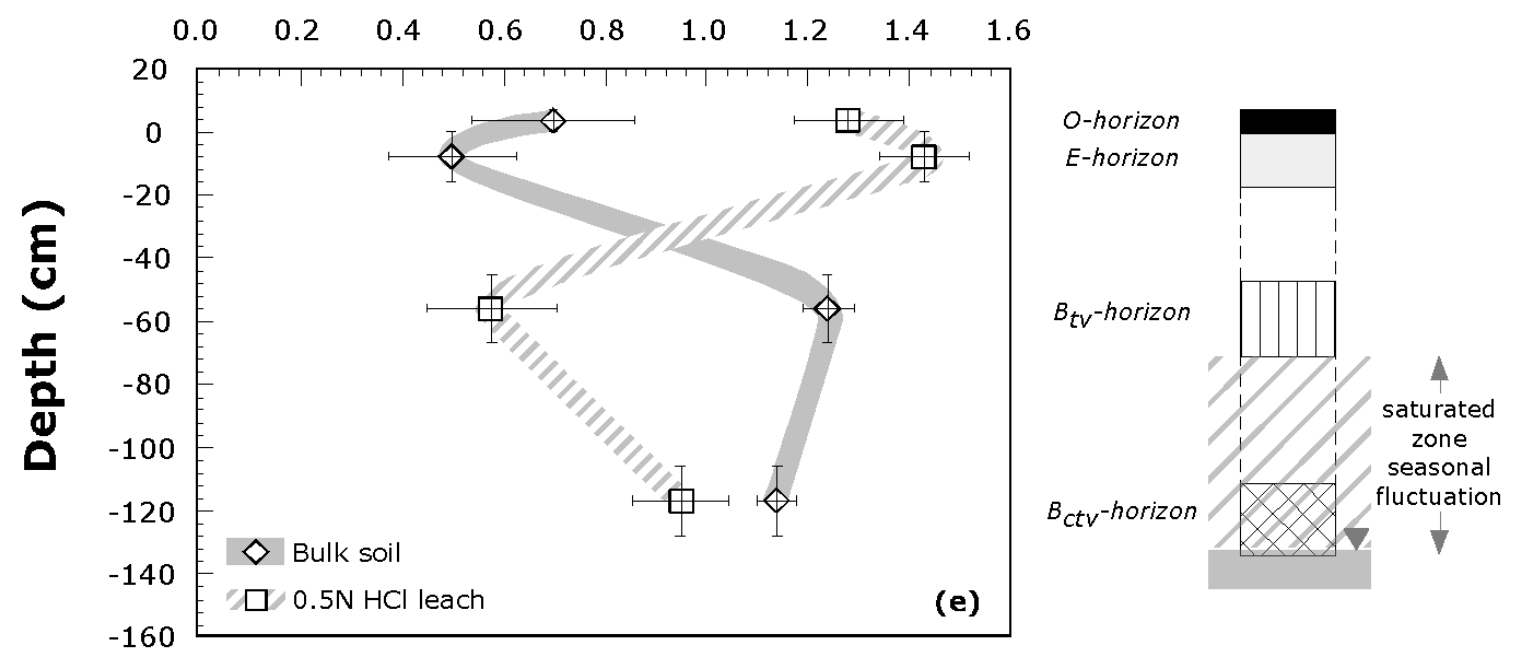


Figure 4

\begin{tabular}{c}
\hline Fe fluxes \\
$\left(\right.$ Tmol Fe $\left.y^{-1}\right)$ \\
\hline
\end{tabular}

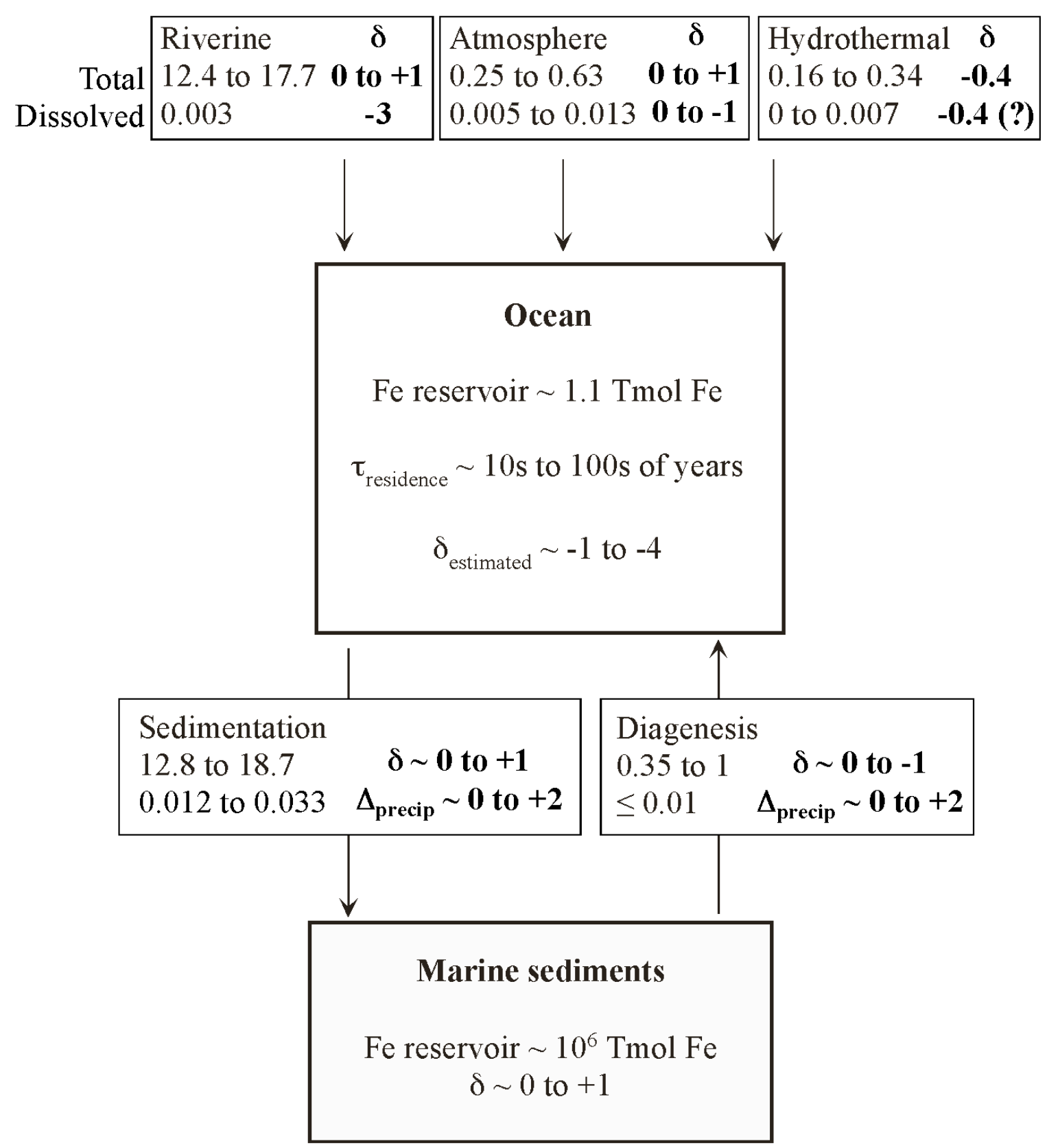

